\title{
Una visión personal de la endocrinología en Chile $^{1}$
}

\author{
Alfredo Jadresic V FRCP2 \\ A personal view of endocrinology \\ in Chile
}

In a short historical review of the outstanding changes occurred in the whole of endocrinology and particularly in Chile over the last 60 years -with the background of an infant mortality drop from 200 per thousand in 1940 to 8 per thousand today and a mean life expectancy increase from 42 to 76 years- the author outlines major achievements in this country. He comments on the use in former days of biological tests on urine extract to measure hormones for diagnostic procedures replaced by hormone determinations in blood by radioimmunoassays; today's medication with synthetic hormones instead of opotherapeutic preparations obtained from organ extracts; the identification of new hormones, receptors and new knowledge that enables us to understand the role of neurotransmitters and neuromodulators, the interaction of neurological, endocrine and immunological systems and the involvement of stress in various diseases. Finally the description of DNA and the international cooperative project to establish the human genome map with unpredictable potential applications in medicine. The author underlines the importance of collaborative work in all branches of medicine, often making cooperation more effective than competition. The enormous expansion of biological information demands that direct application of scientific knowledge to clinical medicine is prevented as being insufficient for an optimal clinical judgment, since a bio-psychosociological perspective of the patient and the doctor's clinical experience are essential factors in the doctor-patient relationship (Rev Méd Chile 2005; 133: 729-36).

(Key Words: Delivery of health care; Endocrinology; History of Medicine, $20^{\text {th }}$ Century)

Recibido el 14 de diciembre, 2004. Aceptado el 15 de marzo, 2005.

${ }^{1}$ Texto de la Conferencia dictada en el XV Congreso Chileno de Endocrinología y Diabetes, y Jornadas Chileno Argentinas. Concepción 13 de noviembre de 2004.

${ }^{2}$ Profesor Emérito, Universidad de Chile. Fellow del Real Colegio Médico de Londres.

$\mathrm{M}$ e he propuesto tratar algunos momentos de la medicina y la endocrinología del siglo XX. Más que simple evocación, espero sean estímulo al pensamiento. La mirada histórica nos permite, tal vez, orientaciones útiles para nuestra sociedad. Pretendo simplemente evidenciar algunos cam-

Correspondencia a: Dr. Alfredo Jadresic V. Av. El Cerro 1827, Depto. 402, Providencia, Santiago, Chile. Fono/Fax: (56-2) 4743720. E-mail: alfredojadresic@vtr.net bios sorprendentes que han ocurrido en el lapso de la vida de un individuo. Inmensas innovaciones que hoy día damos por concedidas y que eran impensables 50 ó 60 años atrás. El acelerado ritmo de avances en las ciencias y las tecnologías impone a nuestra sociedad la responsabilidad de mantener la vista en las proyecciones posibles, sobre todo en las áreas de investigación y en la formación de nuevos endocrinólogos. 
Las profesiones se justifican en función de la sociedad. En esta observación personal tomaré como referencia inicial a la sociedad chilena del cuarto centenario de la fundación de la ciudad de Santiago: febrero de 1941. Yo tenía 15 años y comenzaría a estudiar medicina dos años después. Chile contaba 5 millones de habitantes. La población rural era de 50\%.

Santiago era una ciudad con menos de un millón de habitantes. El límite urbano hacia el oriente era la avenida Tobalaba, donde comenzaban las quintas de frutales. Circulaban carretelas tiradas por caballos y pocos automóviles. Todas las tardes los suplementeros emprendían una carrera desde el local de imprenta de los diarios, con 30 ó 40 ejemplares bajo el brazo, vendiéndolos al recorrer las calles hacia los sectores residenciales. El más veloz vendía más. Ellos fueron los atletas que dieron a Chile muchos premios sudamericanos en las carreras de fondo de 5 y $10 \mathrm{mil}$ metros planos.

La tuberculosis y la fiebre tifoidea eran las principales patologías en adultos. No existían los antibióticos. La desnutrición y las enfermedades infectocontagiosas determinaban una mortalidad infantil de 200 por mill; hoy es 8 por mil. La esperanza promedio de vida era de 42 años; hoy es de 76 años.

Chile se debatía entre el subdesarrollo y la desesperanza. El nivel de pobreza era deprimente. En los consultorios de Santiago se podía ver obreros y campesinos descalzos. Otros usaban "ojotas", hechas con pedazos de neumáticos. El espíritu de la época no podía alentar la ambición de ser rico. En las familias adineradas eran normas la sobriedad y falta de ostentación. No cabía la sociedad de consumo. Se vivía en la sociedad del ahorro.

Se practicaba el deporte estrictamente amateur. Los estudiantes universitarios participaban por su universidad. Los deportistas no ganaban premios en dinero ni hacían anuncios comerciales en sus camisetas. Tampoco aparecían en órganos de publicidad recomendando productos. Los deportistas profesionales no competían en las Olimpíadas.

Existían 3 Facultades de Medicina. La Universidad de Chile aceptaba en primer año 50 estudiantes chilenos y una veintena de estudiantes latinoamericanos de países de la costa del Pacífico y de Centroamérica, algunos de los cuales carecían de escuelas de medicina. La Universidad de Concepción y la Universidad Católica recibían 25 alumnos cada una. Los últimos años de enseñanza clínica se cursaban sólo en la Universidad de Chile. El 97\% de los alumnos pertenecía a la clase media. Los jóvenes de familias ricas no se interesaban en las carreras universitarias. Algunos se matriculaban en la Facultad de Derecho. La mayoría optaba por seguir los negocios familiares, manejar los latifundios o trabajar en la Bolsa.

La mejor enseñanza se daba en los liceos estatales y en la Universidad de Chile. Aunque la educación era gratuita, los jóvenes de familias obreras y campesinas, salvo raras excepciones, no podían optar a la Universidad: debían contribuir tempranamente al sustento familiar.

Los médicos aspiraban a obtener cargos en los hospitales de la Beneficencia Pública o en los Consultorios del Seguro Obrero. Algunos ingresaban a las fuerzas armadas y unos pocos a las universidades. Los médicos que no lograban un cargo solicitaban a los jefes de Cátedra o de Servicio trabajar voluntariamente en los hospitales, porque la concurrencia a los servicios clínicos proveía el proceso de educación continua y la posibilidad de especialización. Cuando en 1952 se constituyó el Servicio Nacional de Salud, más de $90 \%$ de los médicos fueron funcionarios del Estado. Se crearon luego los cargos de médicos generales de zona y las becas de especialización.

Se concurría a los hospitales en las mañanas y se atendía la consulta privada en las tardes. Hacia el final de la jornada, los médicos -incluidos los profesores de la Facultad- controlaban sus pacientes a domicilio. Existían sólo la Clínica Santa María y algunas otras menores que se usaban principalmente como maternidades y para las intervenciones quirúrgicas. Se desconocían las unidades de tratamiento intensivo.

El prestigio no se reflejaba en el nivel económico. Era costumbre no cobrar la consulta a los médicos ni a sus familiares, ni a los amigos cercanos, ni a los pobres. Se consideraba éticamente reprochable hacer propaganda de cualquier clase. En la carrera profesional de los médicos, la distinción mayor era ser Profesor de la Facultad de Medicina de la Universidad de Chile. 
Recién comenzaban a formarse las subespecialidades de la medicina. La endocrinología, como especialidad clínica, era incipiente en el mundo entero e inexistente en Chile. Sin embargo, dos médicos se distinguieron tempranamente en esta disciplina. El Profesor Alejandro Lipschütz, quien hizo contribuciones originales a la tumorigénesis ovárica experimental ${ }^{2}$ y el Profesor Eduardo CruzCoke, quien escribió, entre nosotros, el primer libro sobre bioquímica endocrinológica, titulado "La Corteza Suprarrenal"3.

Por aquellos años, algunas enfermedades, como el aldosteronismo, no se habían descrito. La hiperprolactinemia, en cambio, se había descrito con tres nombres diferentes: síndrome de Forbes y Albright, síndrome de Argonz y del Castillo, y síndrome de Chiari-Frommel, según si el síndrome galactorrea-amenorrea se presentaba con tumores hipofisiarios, sin tumores hipofisiarios evidentes 0 como síndrome persistente post-parto. Hay que recordar que sólo en 1971 se logró resolver la existencia de la prolactina humana como una hormona independiente de la hormona de crecimiento. Se desconocían también las enfermedades inmunológicas.

Los médicos dependían de su experiencia clínica para el diagnóstico de la insuficiencia suprarrenal o la enfermedad de Cushing. No se había logrado hacer mediciones hormonales en la sangre. La determinación de los electrolitos era incierta. Métodos confiables para medir las hormonas adrenocorticales en la orina se introdujeron en clínica sólo a mediados de los años 50. Se utilizaban tests biológicos. En el $10^{\circ}$ piso del Hospital San Juan de Dios instalamos un vivero de ratones para la investigación de las gonadotrofinas. Un arriero de la cordillera nos proveía de sapos para el test de embarazo de Galli Mainini.

Los primeros tratamientos endocrinos se iniciaron a fines del siglo XIX. George Murray, en 1891, comunicó por primera vez la mejoría de un paciente de mixedema con inyecciones de tejido tiroideo. Le precedió, en realidad unos años antes -sin convencer- Brown-Séquard, comunicando los efectos personales vigorizantes logrados con inyecciones de extractos testiculares de perro y cobayo. Se abrió así tempranamente en el siglo $\mathrm{XX}$ el uso de productos opoterápicos. Algunos de éstos se mantuvieron hasta años recientes, como el extracto tiroideo que se obtenía desecando la glándula de buey y prensando el polvo en comprimidos de 65 miligramos (un "grain" anglosajón) y la hormona de crecimiento obtenida de hipófisis humana, hoy suprimida. Se mantienen aún los estrógenos conjugados equinos y las insulinas porcina y bovina, consecutivas al aislamiento de la hormona por Banting y Best en 1922. No existían las hormonas puras sintéticas como la levo-tiroxina, ni las insulinas biosintéticas que sólo se incorporaron en los años 80. Se usaban extractos de corteza suprarrenal de dudosa efectividad. No se había descubierto la cortisona.

A mediados del siglo XX se iniciaron los tratamientos endocrinos para el cáncer avanzado de mama. Charles B Huggins obtuvo el Premio Nobel en 1966, por su contribución al tratamiento hormonal del cáncer prostático. Las limitaciones de la medicina de la época condicionaban la conducta de los médicos hacia sus pacientes. En una encuesta realizada en 1961 en los Estados Unidos, $88 \%$ de los médicos encuestados tenía por norma no comunicar el diagnóstico de cáncer a los pacientes. La costumbre entre nosotros era informar al pariente más cercano. En la encuesta repetida en 1979 en los Estados Unidos se evidenció el cambio: 98\% manifestó tendencia a informar del diagnóstico a los enfermos. Actualmente se tiende a evaluar cada situación. Si bien es cierto que todos tienen derecho a conocer la verdad, ocasionalmente ocurre que algunos pueden no estar realmente preparados para recibir la información. Informar al pariente más cercano puede crear un conflicto con la voluntad de quien no desea que miembros de su familia se involucren en la situación. Hoy se enseña a los estudiantes de medicina la manera adecuada de decir la verdad al paciente.

Hacia mediados de los años 50 se crearon en Santiago, en los hospitales del Salvador, San Juan de Dios y Hospital Clínico de la Universidad de Chile, las primeras Unidades de Radioisótopos, lo que dio un gran impulso al desarrollo de la endocrinología.

$\mathrm{Al}$ igual que en todo el mundo, las unidades de radioisótopos estuvieron inicialmente en manos de los endocrinólogos -por el uso más frecuente en las afecciones tiroideas- pero gradualmente dieron curso a los Departamentos o 
Servicios de Medicina Nuclear y al reconocimiento de esta especialidad.

La endocrinología abrió también otros campos. Los endocrinólogos fueron los primeros en manejar los anticonceptivos, supervisar los tratamientos con cortisona, iniciar el tratamiento de los cánceres hormono-dependientes y los prolactinomas, la osteoporosis, estudiar las hiperlipidemias, destacar las proyecciones patológicas de la obesidad y del estrés, etcétera. A medida que se ha ganado experiencia en estas materias y definido su manejo, ellas se han ido incorporando a la medicina interna o a otras especialidades clínicas.

A comienzo de los años 60, se habían formado varios grupos nuevos de endocrinólogos, en Santiago y en provincias.

Durante los años 1965 y 66 tuve el honor de presidir la Sociedad de Endocrinología. La participación de diversos grupos en el Primer Congreso de Endocrinología, realizado en 1966, mostró el buen nivel de la especialidad alcanzado entre nosotros.

La demanda de cursos y conferencias de los médicos generales y el interés particular de algunos médicos jóvenes hicieron presente la falta de un texto de endocrinología en español. Invité oficialmente, a través de la Sociedad, a los miembros que estuviesen interesados en colaborar en la redacción de un texto. Se propuso, y aceptó, que los autores de los diversos capítulos fueran seleccionados de acuerdo a las publicaciones que hubiesen realizado $u$ otras muestras de conocimiento especial sobre las materias. Fue notable la armonía con que se logró seleccionar a los co-autores y el cumplimiento que todos dieron a la tarea.

De este modo, en 1968, fue editado por la Universidad de Chile el texto "Endocrinología. Fundamentos y Clínica"4, prologado por el Profesor Alejandro Lipschütz. Fue el primer texto clínico editado por colaboración de múltiples autores en Chile.

No pude mantener las reediciones periódicas, por mi alejamiento del país en 1973, pero afortunadamente, otros académicos han continuado la tarea en excelente forma, primero el Dr. Hugo Pumarino ${ }^{5}$ del Hospital Clínico de la Universidad de Chile y recientemente el Dr. José Adolfo Rodríguez ${ }^{6}$ del Hospital Clínico de la Universidad
Católica, además de otros en endocrinología ginecológica y endocrinología pediátrica.

En 1960, tras leer la primera publicación de Salomón Berson y Rosalyn Yalow sobre la determinación de insulina en la sangre por radioinmunoensayo, le escribí una carta al Dr. Berson solicitándole que me permitiera asistir a su laboratorio para aprender estas técnicas. Estuve 2 meses en su laboratorio y el Dr. Berson aceptó mi invitación de venir a Chile. Estuvo durante 4 semanas trabajando en el Laboratorio de Endocrinología del Hospital San Juan de Dios y realizó con nosotros las primeras determinaciones de insulina. En esos años, el procedimiento demoraba varios días. Era necesario producir los propios anticuerpos. Pronto se estandarizaron las técnicas y rápidamente se difundió su uso.

La incorporación de los radioinmunoensayos significó, hacia fines de los 60, una verdadera revolución en el estudio de los pacientes. Otro paso de gran importancia ocurrió, a partir de los años 70, con la aplicación a la clínica de la ecografía, la tomografía computarizada y la resonancia magnética.

Hacia la mitad del siglo XX, la endocrinología logró notables descubrimientos esclarecedores. Gran significación tuvieron las primeras investigaciones sobre interacciones hormonales, por las cuales el Dr. Bernardo A Houssay recibió el Premio Nobel en 1947. El conocimiento de las relaciones del hipotálamo con la hipófisis, iniciado por Harris en 1948 y la identificación de las hormonas hipotalámicas lograda por Schally y Guillemin -quienes obtuvieron el Premio Nobel en 1977- fueron hallazgos fundamentales. Sus proyecciones más allá de la endocrinología, continúan hoy con los estudios de los neurotransmisores y neuromoduladores. Se incorporaron pronto nociones sobre los mecanismos de acción endocrina a nivel celular, los efectos autocrinos y paracrinos de las hormonas y el estudio de los receptores específicos y los factores de crecimiento.

Entre tanto, en 1953, Crick y Watson describieron la estructura del ADN, considerado el descubrimiento más importante de la historia de la biología. En 1986, se inició el estudio internacional cooperativo para establecer el mapa del genoma humano, abriendo inimaginables perspectivas para la medicina. No hay indicios de que 
el ritmo de estos descubrimientos disminuya en los años futuros.

Hasta poco más de 1973, las más modernas tecnologías de la medicina tenían lugar en los centros docentes de la Universidad de Chile, en los grandes hospitales estatales.

La endocrinología clínica se ha desarrollado estrechamente vinculada a las actividades académicas. La Reforma Universitaria de $1968^{7}$ causó, indirectamente, un impacto significativo en la carrera de los endocrinólogos.

Las cátedras universitarias, hasta entonces, mantenían la estructura inalterada de las universidades europeas del siglo XIX. Pero, los avances en las ciencias biológicas y la complejidad creciente en las disciplinas clínicas, hacía mucho tiempo que habían cambiado la práctica de la investigación y la docencia en medicina. Las cátedras y los Servicios clínicos se habían ampliado y diversificado. Existían Servicios en Santiago que sobrepasaban 80 ó 90 docentes. Ya no era posible que un profesor de clínica dictara todas las clases de un curso, como lo hicieron mis maestros. No obstante, las funciones, el destino y la carrera de los docentes eran decididos por la voluntad y el patrocinio del Jefe de Cátedra.

Surgieron, entonces, las demandas de participación de los docentes en las decisiones académicas y las exigencias de los estudiantes de ser escuchados. La situación hizo crisis y tuvo lugar la Reforma Universitaria. Comenzó en la Universidad Católica donde logró un cauce de avenimiento el que fuera nuestro querido Cardenal Silva Henríquez. Gradualmente la Reforma se extendió a todas la universidades. Se establecieron los Departamentos en reemplazo de las cátedras. Los docentes adquirieron representación en los consejos directivos. La evaluación académica se realizó por comisiones especiales y se obtuvo la independencia entre la carrera académica y la línea administrativa del Departamento ${ }^{7}$.

Se inició también el reconocimiento a las especialidades derivadas de la medicina interna. Puedo ilustrar, anecdóticamente, que mi nombramiento de Profesor Extraordinario de Medicina, cumplida la exigencia reglamentaria -4 años como Profesor Encargado de Curso, 4 años de Profesor Auxiliar y aprobada mi tesis sobre La Hipofisectomía en Clínica- dio origen en la Facultad de la época -justo antes de la Reforma de 1968- a la discusión sobre la propiedad o no de que un "especialista" obtuviera el grado académico de Profesor Extraordinario de Medicina, en esos años, paralelo al de Profesor Titular. Con la Reforma se afianzó el derecho a la carrera académica en endocrinología.

La vida institucional fue afectada gravemente por la dictadura que siguió al golpe militar de 1973. Sucedió un gran retroceso en el desarrollo histórico de las universidades. Se implantó la intervención militar en todas ellas y un sistema autoritario que negaba la participación.

La reestructuración económica y administrativa que tuvo lugar después de 1973, la drástica limitación del gasto público en los sectores salud y educación, la interdicción de las universidades, la disgregación de la Universidad de Chile, el desmantelamiento de unidades hospitalarias, colocó a los endocrinólogos en situaciones muy difíciles. No fui testigo de esos tiempos, porque debí partir al destierro, pero conocí los estragos a mi regreso. El Laboratorio de Investigaciones Endocrinas del Hospital San Juan de Dios, que había alcanzado un lugar de relevancia, se consideró prescindible y el personal fue dispersado o despedido.

Se puso el énfasis en la atención primaria a costa del nivel mínimo requerido por el sector terciario. Los endocrinólogos hicieron ingentes esfuerzos por mantener la endocrinología clínica en los niveles de la práctica en los grandes centros internacionales.

Afortunadamente, desde su fundación en 1972, la Unidad de Endocrinología de la Universidad Católica logra mantener un ritmo sostenido de expansión y progreso.

Al término del gobierno militar, fue notable el cambio ocurrido en la medicina. Los hospitales estatales, otrora los mejores dotados, presentaban tal carencia de equipamiento que eran deficitarios de los medios necesarios para la enseñanza.

En 1990, se me solicitó reorganizar la enseñanza de postgrado, lo que logramos, desde el Departamento de Recursos Humanos del Ministerio de Salud, en colaboración con las seis Facultades de Medicina de entonces. Tuvimos que recurrir al sector privado para enseñar las técnicas modernas de imagenología, porque ningún hospi- 
tal del Estado contaba con un escáner. Habían surgido en cambio las clínicas privadas con los más modernos equipamientos. En años recientes la situación de los hospitales estatales ha mejorado un tanto.

En lo que respecta a nuestra relación con la medicina general, la municipalización -que introdujo la segregación del nivel primario del sistema hospitalario- no ha encontrado solución adecuada. Desde el Ministerio de Salud propusimos la creación de Centros de Referencia ${ }^{8}$, como lugares principales de relación entre los especialistas del hospital y los médicos generales. Los centros de referencia que se han creado en Santiago son autónomos y no cumplen la finalidad original.

Durante los 15 años de mi exilio en Inglaterra, tuve oportunidad de conocer la interacción de los médicos de familia con los centros hospitalarios. Me correspondía, como Consultor, apoyar el trabajo comunitario en endocrinología y diabetes. Fuera de las conferencias y charlas en el Centro de Medicina de Postgrado -del cual yo era Director en mi distrito- una eficiente vinculación con los médicos generales se producía a través de las interconsultas documentadas. Ello les permitía saber cómo fueron precisados los diagnósticos y conocer los tratamientos. El médico de familia podía mantener el control de sus pacientes y referirlos al especialista sólo en caso necesario. La interacción introduce, de este modo, un proceso de educación continua en la práctica profesional.

Los especialistas, liberados de la atención asistencial masiva, pueden dedicar mucho más tiempo a la investigación clínica. En el Hospital Hammersmith de Londres, el control de los pacientes estabilizados, hipofisiarios, addisonianos 0 tiroideos, se hacía solamente cada 2 a 3 años. El seguimiento más frecuente lo efectuaba el médico de familia.

La Sociedad Chilena de Endocrinología -desde su fundación en 1958- ha jugado un rol esencial en el desarrollo de la especialidad. Es la instancia de encuentro personal entre los especialistas y contribuye a la formación de nuevos endocrinólogos. Es una sociedad de gratas relaciones humanas y un ambiente estimulante. El aumento de las clínicas privadas con buenos equipamientos y su vinculación con las universidades privadas ha creado nuevos centros de endocrinología. Es previsible que estos centros encontrarán aquí el cauce natural de comunicación y colaboración. La colaboración puede ser más efectiva que la competitividad para el progreso en las actividades humanas.

La propuesta de una endocrinología eficiente en todo el país plantea favorecer la formación integrada en endocrinología y diabetes. Ello permitiría proveer la cobertura de ambas disciplinas en comunidades donde no es posible destinar los dos especialistas; y no es óbice para la opción ulterior de dedicación exclusiva a una u otra de ellas en el nivel terciario.

La expansión de la endocrinología ha determinado gradualmente la asociación en campos específicos dentro del panorama global de la especialidad, como la endocrinología pediátrica y ginecológica, el climaterio, la obesidad, la osteoporosis, la neuroendocrinología y otros. En estas áreas ocurren descubrimientos y experiencias que son útiles para los endocrinólogos generales o dedicados a áreas diferentes. Es recomendable mantener algún tipo de relación entre estos grupos, tal como ocurre con gran beneficio con la participación en nuestras jornadas de investigadores básicos y clínicos. Tal vez sería conveniente efectuar las reuniones anuales de las diversas asociaciones en forma simultánea y paralela, lo que permitiría la programación independiente de ellas, pero con la opción de interrelaciones de vecindad o de participación común en algunos temas.

Dentro de estas consideraciones, uno de los hechos más relevantes para la clínica ha sido el conocimiento sobre las interrelaciones de los sistemas nervioso, endocrino e inmunológico ${ }^{9}$. Tempranamente, el conocimiento de la íntima relación entre el sistema nervioso y el sistema endocrino condujo en propiedad al concepto de un sistema neuroendocrino. Y con ello al entendimiento de las influencias psicológicas y ambientales en el funcionamiento hormonal.

Son particularmente pertinentes las reacciones del sistema neuroendocrino frente al estrés ${ }^{10}$. Cada vez es mayor el acopio de información sobre la significación patológica de la participación del sistema simpático adrenomedular en los estados de excitación aguda y del eje hipotálamo-hipófisis-corticosuprarrenal en las condiciones de estrés 
crónico. La disregulación de este último en la depresión es uno de los hallazgos más consistentes de la psiquiatría biológica.

El cambio ocurrido en salud en nuestra sociedad en el último medio siglo es inmenso. Superados los niveles de mayor pobreza, las enfermedades infectocontagiosas, la desnutrición, la tuberculosis; logrados progresos extraordinarios en el control de la mortalidad infantil y en la extensión de vida de la población, hace irrupción el estrés como un factor primordial de morbilidad.

Entre los efectos dañinos del estrés crónico, McEwen ${ }^{11}$ destaca una mayor incidencia de diabetes, resistencia a la insulina, riesgo de enfermedades cardiovasculares, y una relación entre el estrés y la obesidad abdominal, la hipertensión y la arterioesclerosis.

Resulta particularmente importante, en la vida moderna, atender a factores que afectan la salud mental, porque son causas comunes de estrés crónico las condiciones socioeconómicas adversas, la cesantía, el agobio del trabajo, la mala adaptación ambiental, la soledad y la depresión.

Según Brenner y cols ${ }^{12}$, el estrés crónico por desempleo prolongado ocasiona, estadísticamente, aumento de la morbilidad y mortalidad.

Se ha agregado posteriormente mayor conocimiento del sistema inmunológico, el cual aparece sometido a controles neuronales y endocrinos y a su vez, recíprocamente, ejerce efectos sobre el sistema nervioso y el sistema endocrino. Las relaciones entre los tres sistemas, establecidas en las últimas décadas, ha conformado poco a poco el concepto de una integración neuro-inmunoendocrina.

En una atractiva concepción, Blalock ${ }^{13}$ ha propuesto considerar a los linfocitos y monocitos periféricos como un mecanismo sensorial del sistema inmunológico para el reconocimiento de substancias extrañas, infección o daño tisular y para la movilización de la respuesta neuroendocrina.

Danzer $^{14}$ considera que la información actual sobre estas relaciones permite cerrar el círculo de interrelaciones psico-neuro-inmuno-endocrinas de modo que no sólo la conducta y los estados mentales afectan las respuestas inmunológicas sino que, a su vez, las citokinas ejercen influencia sobre la conducta.
Glaser et $\mathrm{al}^{15}$, entre otros, han comprobado alteraciones de los procesos inmunológicos en las personas que sufren estrés prolongado.

En las últimas décadas el aporte de la genética a la endocrinología permite el esclarecimiento de algunos problemas fundamentales de la diversidad humana frente a las patologías. Se ha demostrado que la calidad de la respuesta a los factores estresantes pueden también ser determinadas por factores genéticos. Los trabajos de Panarelli et al ${ }^{16}$ sobre el polimorfismo de los receptores de glucocorticoides demuestran que el genotipo del receptor afecta la sensibilidad de los diversos tejidos del organismo de una manera específica, que puede provocar alteraciones de funciones incluso en ausencia de hiperactividad del eje de la hormona liberadora de corticotrofina.

Así, teóricamente, los efectos conocidos del exceso de glucocorticoides como hipertensión, osteoporosis, inmunosupresión, obesidad visceral, dislipidemia, resistencia a la insulina, etc., pueden ocurrir selectivamente en personas que evidencian valores circulantes normales de cortisol.

La variedad de estímulos físicos, psicológicos y sociales que afectan el curso de la vida y la complejidad multifactorial y poligenética que condiciona la respuesta del individuo, hacen del estrés un tema fundamental para la comprensión de la salud y la enfermedad.

Los análisis científicos de los últimos años han establecido gran confianza en la medicina basada en la evidencia. No obstante, la experiencia clínica modera esa confianza frente a las variaciones de las respuestas individuales. Ello conduce a la necesidad del enfoque antropológico de la medicina y a la apreciación holística del paciente. Ya en 1882, en su clase inaugural el profesor vienés Hermann Nothnagel ${ }^{17}$, se dirigía a sus alumnos diciendo: "El objeto de la medicina es el tratamiento de los enfermos, no de las enfermedades". El mismo enfoque humanista destaca, años más tarde, en la Universidad de Johns Hopkins, Sir William Osler, el más grande innovador de la medicina moderna de los Estados Unidos. Estos conceptos mantienen plena vigencia.

$\mathrm{Si}$ bien es innegable la importancia del rigor científico en las investigaciones clínicas, no lo es menos que la medicina basada en la evidencia encuentra límites en la aplicación directa a un 
paciente individual y es insuficiente para proveer el óptimo juicio clínico. Es indebido y reduccionista adoptar el conocimiento científico como el único factor sobre el cual debe basarse la decisión del médico, suplantando la experiencia clínica. La experiencia es ella misma una reflexión válida.

En las últimas décadas, ha resurgido paralelamente a la medicina basada en la evidencia, el énfasis en la medicina centrada en el paciente. Se propone considerar los juicios clínicos en el contexto y la perspectiva de la historia biomédica y psicosocial de la persona. El buen criterio señala

\section{REFERENCIAS}

1. Auende S. La Realidad-Médico Social Chilena. $2^{\mathrm{a}}$ edición. Santiago: Editorial Cuarto Propio. 1999.

2. Lірschüтz A. Differential evolutionary patters of experimentally induced ovarian tumors. Perspect Biol Med 1968; 11: 461-74.

3. CRuz-Coke E. La Corteza Suprarrenal. Santiago: Nascimento. 1942.

4. JADRESIC A. Endocrinología. Fundamentos y Clínica. Santiago: Ediciones de la Universidad de Chile. 1968.

5. Pumarino H. Endocrinología y Metabolismo. 2a Edición. Santiago: Editorial Andrés Bello. 1984.

6. Rodríguez JA. Endocrinología Clínica. Santiago: Mediterráneo. 2000.

7. JADRESIC A. La Reforma de 1968 en la Universidad de Chile. Con especial referencia a la Facultad de Medicina. Santiago: Editorial Universitaria, 2002.

8. JADRESIC A. Hacia una política de desarrollo de recursos humanos para la salud. Rev Méd Chile 1991; 119: 589.

9. JADRESIC A. Interacciones inmuno-neuroendocrinas. Rev Chile Neuro-Psquiat 1993; 31: 305.

10. JADRESIC A. Relaciones psiconeuroendocrinas del estrés. En: Jadresic A, Ojeda C, Pérez G: Psiconeuroendocrinología. Santiago: Mediterráneo 2000; $13-25$. la conveniencia de combinar ambos enfoques, dando la debida atención a la interacción humana.

$\mathrm{Al}$ término de este bosquejo sobre algunos momentos del desarrollo de la medicina, podemos decir que la endocrinología, desde la fisiopatología y la clínica, desde la biología molecular y la bioquímica de sistemas, la genética y la inmunología, hasta la psiquiatría y la salud pública, nos acerca, como ninguna otra disciplina, de una manera integral, a la mejor comprensión del ser humano y a la reflexión sobre el maravilloso misterio de la vida.

11. McEwen BS. Protective and damaging effects of stress mediators. N Engl J Med 1998; 338: 171-9.

12. BRENNER MH. Mortality and the national economy. Lancet 1979; ii: 568-73.

13. BцаLOCK JE. A molecular basis for bi-directional communication between the immune and neuroendocrine systems. Physiol Rev 1989; 69: 1-32.

14. DANZER R. Stress and immunity: what have we learned from psychoneuroimmunology? Acta Physiol Scand 1997; 161 (Suppl 640): 43-6.

15. Giaser R, Kiecolt-Giaser J. Handbook of Human Stress and Immunity. San Diego: Academic Press, 1994.

16. Panarem M, Howoway CD, Fraser R, ConNell JM, IngRam MC, ANDERSON NH ET AL. Glucocorticoid receptor polymorphism, skin vasoconstriction, and other metabolic intermediate phenotypes in normal human subjects. J Clin Endocrinol Metab 1998; 83: 1846-51.

17. Max Neuberger, Hermann Nothnagel. Leben und Wirken eines deutschen Klinikers. Vienna 1922, pp. 146, n. 20. Citado por Porter R: Cambridge Illustrated History of Medicine. Cambridge University Press 1996, reprinted 2000. p. 143.

18. Porter R. Cambridge Illustrated History of Medicine. Cambridge University Press 1996. Reprinted 2000. Pássim. 